\title{
Compositional layering in a highly diamondiferous eclogite xenolith from the Roberts Victor kimberlite, South Africa and its implications for diamond genesis
}

\author{
Akira Ishikawa ${ }^{1}$, D. Graham Pearson ${ }^{1}$, Shigenori Maruyama ${ }^{2}$, \\ Pierre Cartigny ${ }^{3}$, Richard A. Ketcham ${ }^{4}$, John J. Gurney ${ }^{5}$ \\ ${ }^{I}$ Dept. of Earth Sciences, Durham University, Durham, UK \\ ${ }^{2}$ Dept. of Earth and Planetary Sciences, Tokyo Institute of Technology, Tokyo, Japan \\ ${ }^{3}$ Institut de Physique du Globe and Universite de Paris 7, Paris, France \\ ${ }^{4}$ Dept. of Geological Sciences, University of Texas at Austin, Austin, USA \\ ${ }^{5}$ Dept. of Geological Science, University of Cape Town, Rondelbosch, South Africa
}

The xenocrystic nature of diamonds in kimberlitic magma is widely accepted. In addition to radiometric dating of diamonds, this relationship is firmly supported by the common presence of peridotitic and eclogitic silicate inclusions within diamonds together with the complementary occurrence of diamondiferous peridotite and eclogite xenoliths from worldwide kimberlite locations. Despite this, the nature of diamond formation in these host rocks remains contentious, in part because of the relative rarity of diamondiferous samples that are large enough for comprehensive study. Recent advances in the understanding of diamond formation within eclogitic hosts have been made from systematic studies of diamondiferous eclogites from Yakutia, applying high-resolution X-ray computed tomography (HRXCT) techniques to investigate the spatial and textural relationships between diamonds and other minerals (e.g., Anand et al., 2004). In these studies, eclogitic diamonds always occurred in proximity to clinopyroxene but never fully enclosed within fresh garnet or clinopyroxene. These lines of evidence, together with other evidence

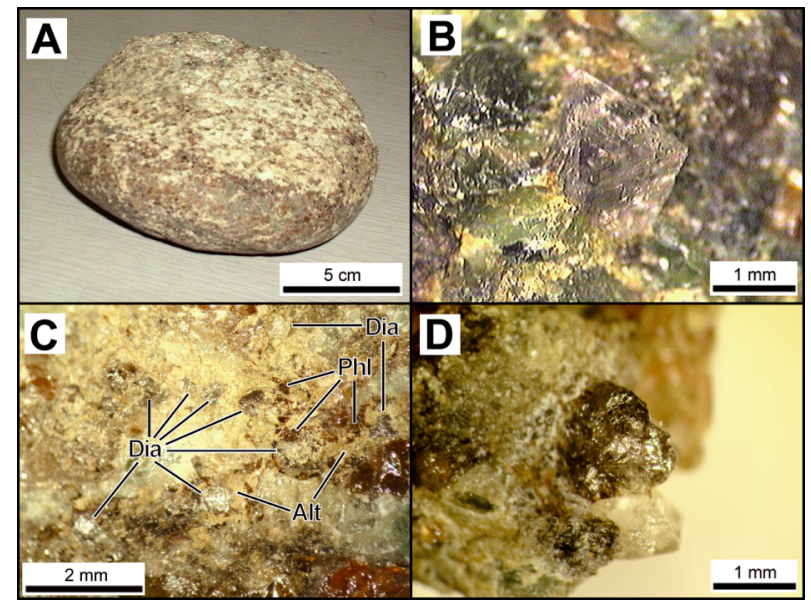

Fig. 1. (A) Photograph of RVSA71 showing the two different zones of the xenoliths. The upper part is clinopyroxene-rich, whereas the lower part is garnet-rich. (B) Diamond octahedra in the clinopyroxene-rich zone. (C) Linear growth of 8 diamonds (Dia) in the garnet-rich zone. The diamonds occurs in a branched vein-like structure marked by abundant phlogopite (Phl) and other alteration products (Alt). (D) Black and colourless polycrystalline diamonds in the garnet-rich zone. from diamonds and their inclusions, have led to suggestions of the metasomatic formation of eclogitic diamonds, post-dating the formation of the host eclogites (e.g., Spetsius and Taylor, 2004). However, this is in apparent conflict with previous studies of two diamondiferous eclogites (HRV247 and RV124) from the Roberts Victor kimberlite, South Africa (Hatton and Gurney, 1979; Jacob and Jagoutz, 1996). These southern African eclogites display systematic changes in diamond (and graphite) abundance within a single nodule that are closely associated with compositional layering in silicates, defined by mineral and modal chemistry. The origin of layering has been attributed to igneous fractionation processes, either in high-pressure (mantle) or low-pressure (crustal) environments. The close association of silicate layering with diamond abundance can be used to imply the syngenetic formation of diamonds with silicates within the host eclogites.

In this study, we report a third example of compositionally layered diamondiferous eclogite (RVSA71) discovered in a new collection from the Roberts Victor Mine. In our preliminary investigation, 94 crystals of diamond ranging in size from 0.5 to $2 \mathrm{~mm}$ in maximum dimension have been recovered from $160 \mathrm{~g}$ of a clinopyroxene-rich part of the specimen, yielding a diamond grade of approximately 8400 carats per metric ton. This high concentration of diamond, the relatively large size of the xenolith host together with its compositional layering, provide a rare opportunity to test whether the diamond formation was contemporaneous with or post-dated the formation of the host eclogite. In order to address this issue, we performed (1) 3D mapping of the rock using the HRXCT technique, (2) major element analyses of garnet and clinopyroxene across the layering by the electron microprobe, (3) analysis of the nitrogen content and aggregation state of the diamonds by Fourier Transform Infrared spectroscopy (FTIR), and (4) Carbon isotope analyses of the diamonds by the conventional combustion technique.

\section{Petrography}

RVSA71 is a rounded $2.6 \mathrm{~kg}$ Group I eclogite xenolith with original dimensions of $15 \times 12 \times 8 \mathrm{~cm}$. This is the largest diamondiferous xenolith studied to date using the 
HRXCT technique. It consists of two zones defined by an abrupt change in the modal proportions of garnet and clinopyroxene (Fig. 1A). Approximately half of the xenolith comprises a clinopyroxene-rich $\left(7_{\mathrm{Cpx}}: 3_{\mathrm{Grt}}\right)$ with the other half being garnet-rich $\left(2_{\mathrm{Cpx}}: 8_{\mathrm{Grt}}\right)$; hereafter referred to as the Cpx-rich and Grt-rich zones, respectively. Garnet in Cpx-rich zone occurs as rounded crystals in a matrix of clinopyroxene and tends to be smaller $(\sim 2 \mathrm{~mm})$ than that in the Grt-rich zone $(<5 \mathrm{~mm})$. Clinopyroxene in Grt-rich zone is clustered with "channel-like" structures, whose orientations are oblique to the plane of the boundary. Both Cpx-rich and Grt-rich zones contain diamond, sulfide and phlogopite as minor constituents, but these phases have distinct spatial distributions and relationships to the main silicate minerals in each zone. These differences are evident from the results of HRXCT performed on xenolith pieces from each zone (Fig. 2).

In Grt-rich zone, the diamonds are occasionally large and very irregular (Fig. 2A). They typically occur in the clinopyroxene-rich patches within this zone, resulting in a strong linear alignment (Fig. 2C). This feature is also confirmed by visual examination of the broken surface, where diamonds occur in vein-like structures of phlogopite and other alteration products developed in clinopyroxene-rich patches (Fig. 1C). In Cpx-rich zone, the diamonds are more abundant and typically euhedral, although some have an unusual flattened habit (Fig. 2B). They are distributed evenly throughout the specimen. The occurrence and abundance of phlogopite is closely correlated with diamonds. HRXCT shows clearly that sulfides are not preferentially associated with diamonds in either Cpx-rich or Grt-rich zones. However, sulfide is apparently absent in the distal end of the Grt-rich zone, where the garnets appear fractured, or at least have very sharp grain boundaries (the upper half of Fig. 2C).

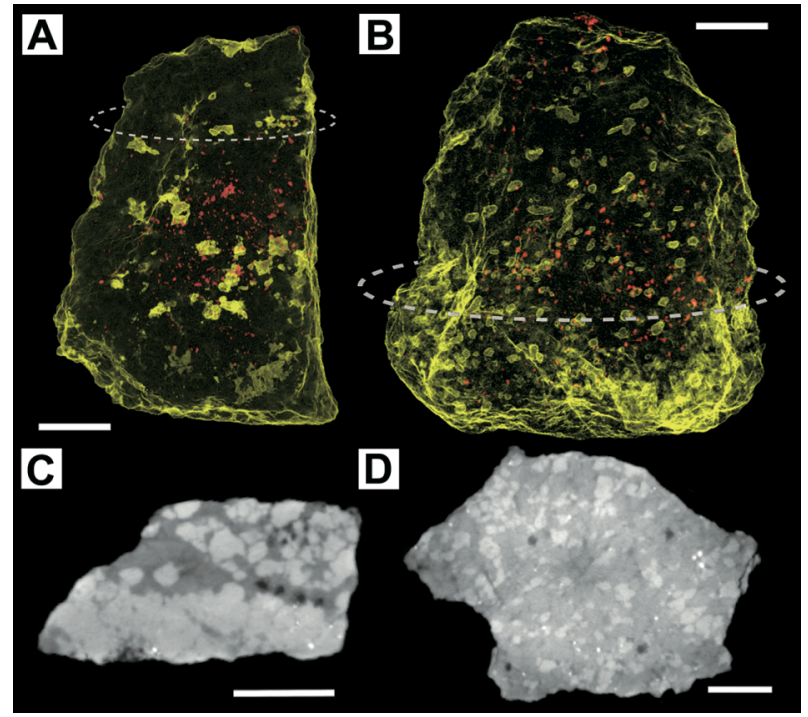

Fig. 2. 3D images of (A) Grt-rich and (B) Cpx-rich zones of RVSA71 constructed from HRXCT. All the minerals except diamonds (yellow) and sulfides (red) have been made invisible to emphasise the diamond and sulfide spatial relationships. The dotted girdle indicates the positions where $2 \mathrm{D}$ slices $(\mathrm{C}$ for $\mathrm{A}$, $\mathrm{D}$ for B) were taken. In these slices, diamond and phlogopite appears black, clinopyroxene as dark grey, garnet as light grey, and sulfide as white. Scale bars $=1 \mathrm{~cm}$.

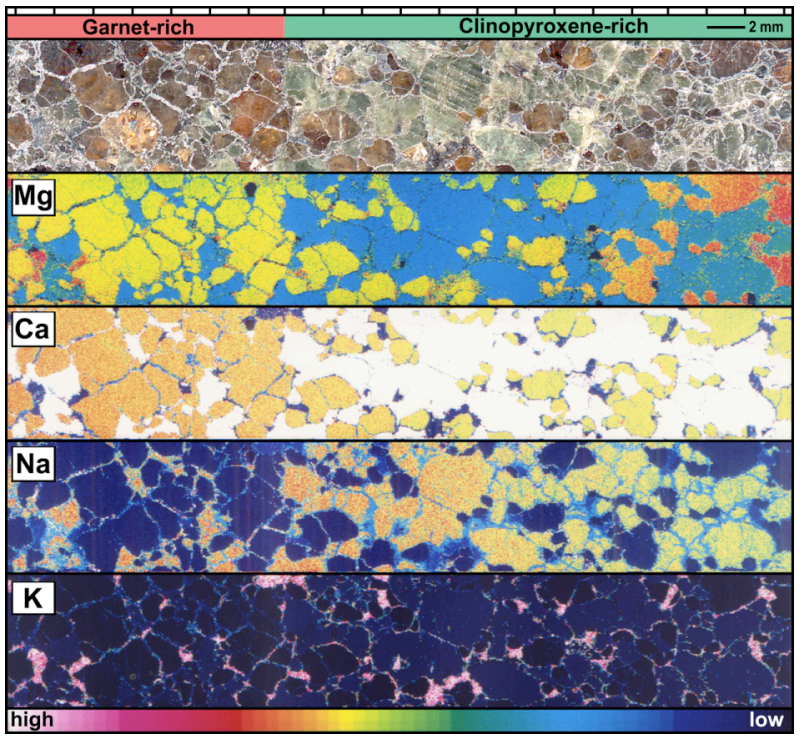

Fig. 3. Photograph (top) and elemental concentration maps (bottom) of the boundary between Grt-rich (left) and Cpx-rich (right) zones of RVSA71.

\section{Mineral chemistry}

The variations in key minor elements such as $\mathrm{K}_{2} \mathrm{O}$ in clinopyroxene $(0.27 \pm 0.06 \mathrm{wt} \%)$ and $\mathrm{Na}_{2} \mathrm{O}$ in garnet $(0.08 \pm 0.02 \mathrm{wt} \%)$ are relatively constant throughout the xenolith. In contrast, the major element chemistry of clinopyroxene and garnet displays systematic changes across the layering. The distal end of the Cpx-rich zone and the opposite end of the Grt-rich zone show the lowest and highest $\mathrm{Na}_{2} \mathrm{O}$ in clinopyroxene (1.7 and 3.2 $\mathrm{wt} \%$ ) and $\mathrm{CaO}$ in garnet (3.6 and $4.7 \mathrm{wt} \%$ ), respectively. This compositional transition is probably continuous throughout the xenolith, and is nearly perpendicular to the plane of the boundary (Fig. 3). Mg-number $[=\mathrm{Mg} /(\mathrm{Mg}+\mathrm{Fe})]$ in both clinopyroxene and garnet decreases systematically from one end (Cpx-rich zone) to the opposite end (Grt-rich zone). Thus, constituent clinopyroxene and garnet are systematically depleted in fusible components such as $\mathrm{FeO}$, jadeite and grossular toward the end of the Cpx-rich zone. Very similar compositional layering has been recognized in diamondiferous eclogite HRV247, although RVSA71 shows a more refractory composition than HRV247.

\section{Diamonds}

The HRXCT results show that there are significant contrasts between the Cpx-rich and Grt-rich zones in terms of diamond contents, spatial distribution patterns, and external form. The detail of this morphological difference has been confirmed by visual examination of diamonds extracted from the two zones. The diamond population in the Cpx-rich part is made up of colourless twinned octahedra. This twinning can take the form of relatively simple twinning such as macles, or can be more complex, resulting in octahedral aggregates. Some diamonds also occur as perfect octahedra (Fig. 1B). By contrast, the majority of the extracted diamonds from the Grt-rich zone exhibit complex aggregated growth forms resulting in polycrystalline diamonds with highly irregular external shapes and dark-grey to black internal colouration (Fig. 1D). 


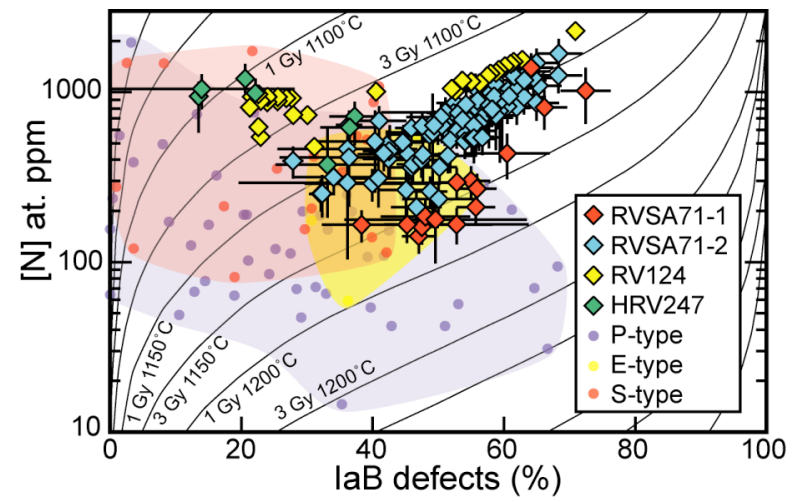

Fig. 4. Nitrogen contents and aggregation states for diamonds in compositionally layered eclogites (diamonds). Also shown are data for diamonds of known inclusion mineral compositions (circles: Deines et al., 1987) from run-of-mine production at the Roberts Victor kimberlite. Data points for RVSA71-1 (14 grains from Grt-rich zone), RVSA71-2 (91 grains from Cpxrich zone), and HRV247 (2 grains from unknown position) represent averaged values for multiple spot analyses on individual broken fragments. Error bars indicate range in individual pieces if larger than experimental precision (defects: $\pm 5 \%$; N-contents: $\pm 20 \%$ ). Data points for RV124 and a series of isotherms are from Taylor and Milledge (1995).

FTIR results show that all diamonds from the xenolith exhibit Type IaAB nitrogen aggregation. Diamonds from the Cpx-rich zone show a positive correlation of nitrogen content and aggregation state, that closely approximate an isothermal relationship (Fig. 4). However, polycrystalline diamonds from the Grt-rich zone tend to deviate below and to the right of the isothermal trend for the Cpx-rich zone, although a rare colourless aggregate from the Grt-rich zone (Fig. 1D) plots within the trend of the Cpx-rich zone. If it is assumed that the same kinetics controlling the nitrogen aggregation for simple octahedra also control the nitrogen aggregation within the complex polycrystalline diamonds, these data may indicate that the xenolith contains at least two diamond populations. In this scenario, the polycrystalline diamonds crystallized first in the Grt-rich zone of the xenolith, and diamonds in the Cpx-rich zone were subsequently formed as another population.

Since the $\delta^{13} \mathrm{C}$ compositions of all the diamonds from RVSA71 fall within a very narrow range (-4.4 to $6.5 \%$ ) typical of mantle-derived carbon, the isotopic variations cannot be used to distinguish possible multiple populations within the xenolith. This raises an alternative possibility that all the diamonds within RVSA71 formed during a single crystallization event, with the different crystal forms reflecting the varying fluid-rock ratios in different parts of the xenolith. In this scenario, we would have to assume that the nitrogen within the polycrystalline diamonds aggregated more rapidly compared to the monocrystalline forms within the Cpxrich zone. The reason for such a difference is unclear.

\section{Concluding remarks}

Although there is no simple model to explain the combined morphological, nitrogen defect and C-isotopic data obtained in this study, we envisage that the highly correlated patterns between diamond and host eclogites were created by an ancient diamond precipitation event (or events) that occurred within the lithospheric mantle beneath the Roberts Victor. The HRXCT results indicate that the diamond crystallization post-dated the formation of the Grt-rich zone, but was contemporaneous in the Cpx-rich zone. Applying these observations to the nitrogen aggregation data, a possible inferred sequence of evolution is (1) formation of silicates in the Grt-rich zone, (2) crystallization of diamonds in Grt-rich zone, and (3) later formation of silicates and diamonds in the Cpx-rich zone during silicate melt metasomatism. This sequence may be explained by a "magmatic model" if the eclogite was originally formed via crystal segregation in a part of a long-lived channel of deeply derived melt. The "metasomatic model" may also work if this channel developed in the pre-existing mantle eclogite whose composition was extensively modified by melt-fluid fractionation processes. The heterogeneous and zoned distribution of diamonds within this large eclogite xenolith indicates that caution needs to be applied to the interpretation of diamond distributions in much smaller eclogite xenoliths studied by the HRXCT method.

The possibility of at least two generations of diamonds in eclogite xenolith RVSA71 is consistent with other FTIR data for diamonds from other diamondiferous xenoliths (e.g. Taylor and Milledge, 1995). If this relationship is common it means that any one-kimberlite pipe is likely to carry a multitude of diamond populations and this makes isochron dating of diamonds from run-of-mine production very difficult unless detailed FTIR data are available. Even then, the chance of including diamonds from different growth populations in the same isochron regression is high and this may explain much of the scatter in the data.

\section{References}

Anand, M., Taylor, L.A., Carlson, W.D., Taylor, D.-H., Sobolev, N.V., 2004. Diamond genesis revealed by X-ray tomography of diamondiferous eclogites. Extended abstracts of the 8th International Kimberlite Conference, Victoria B.C., (CD).

Deines, P., Harris, J.W., Gurney, J.J., 1987. Carbon isotopic composition, nitrogen content and inclusion compositions of diamonds from the Roberts Victor kimberlite, South Africa: evidence for ${ }^{13} \mathrm{C}$ depletion in the mantle. Geochimica et Cosmochimica Acta, 51, 1227-1243.

Hatton, C.J., Gurney, J.J., 1979. A diamond-graphite eclogite from the Roberts Victor mine. In: Boyd, F.R., Meyer, H.O.A. (Eds.), The Mantle Sample: Inclusions in Kimberlites and Other Volcanics. American Geophysical Union, Washington D.C., 29-36.

Jacob, D., Jagoutz, E., 1996. A diamond-graphite bearing eclogitic xenolith from Roberts Victor (South Africa): indications for petrogenesis from $\mathrm{Pb}-, \mathrm{Nd}-$ and $\mathrm{Sr}-$ isotopes. In: Meyer, H.O.A., Leonardos, O.H. (Eds.), Proceedings of the 5th International Kimberlite Conference, Vol.1. Companhia de Pesquisa de Recursos Minerais, Special Publication, 1/A, 304-317.

Spetsius, Z.V., Taylor, L.A., 2004. Metasomatic diamonds in eclogite xenoliths: petrologic and photographic evidence. Extended abstracts of the 8th International Kimberlite Conference, Victoria B.C., (CD).

Taylor, W.R., Milledge, H.J., 1995. Nitrogen aggregation character, thermal history, and stable isotope composition of some xenolith-derived diamonds from Roberts Victor and Finsch. Extended abstracts of the 6th International Kimberlite Conference, Novosibirsk, 620-622. 